\title{
Antiviral Therapy of Liver Cirrhosis Related to Hepatitis B Virus Infection
}

\author{
Lun-Gen Lu* \\ Department of Gastroenterology, Shanghai First People's Hospital, Shanghai Jiaotong University School of Medicine, Shanghai, China
}

\begin{abstract}
Hepatitis B virus (HBV) infection is a leading cause of liver disease worldwide, with $75 \%$ of those affected distributed in the Asia-Pacific region. Approximately one million HBVinfected patients die of liver cirrhosis and hepatocellular carcinoma (HCC) each year. If left untreated, $6-20 \%$ of chronic hepatitis B (CHB) patients will develop cirrhosis over five years. The cumulative incidence of HBV-related cirrhosis, disease progression, and prognosis are closely associated with serum HBV DNA levels. Antiviral therapy in HBV-related cirrhosis has been documented by several long-term cohort studies to decrease disease progression to hepatic decompensation and HCC. The approval and availability of oral antiviral agents with better safety profiles has greatly improved the prognosis for HBV-related cirrhosis. Here, we discuss the significance of antiviral therapy for HBV-related cirrhosis and the management of HBV-related diseases in the future.

(C) 2014 The Second Affiliated Hospital of Chongqing Medical University. Published by XIA \& HE Publishing Ltd. All rights reserved.
\end{abstract}

\section{Introduction}

Hepatitis B virus (HBV) infection, the major cause of liver cirrhosis and hepatocellulcar carcinoma (HCC), is a serious global health concern. The World Health Organization (WHO) reported that approximately $45 \%$ of the population lives in an area with a high prevalence of chronic hepatitis $B(\mathrm{CHB}){ }^{1}$ $\mathrm{CHB}$ is particularly prevalent in the Asia-Pacific region. Of approximately 350-400 million chronically infected carriers, approximately $75 \%$ are found in Asia. ${ }^{2,3} \mathrm{HBV}$ is the tenth leading cause of death worldwide, and each year more than one million chronic HBV carriers worldwide die of liver cirrhosis and $\mathrm{HCC}$, the most severe adverse sequelae of CHB. ${ }^{4}$ Approximately $6-20 \%$ of $\mathrm{CHB}$ subjects will develop cirrhosis within five years if left untreated. The incidence of

Keywords: Hepatitis B virus; Chronic HBV infection; Liver cirrhosis; Antiviral therapy.

Abbreviations: AASLD, American Association for the Study of Liver Disease; $A D V$, adefovir dipivoxil; ALT, alanine transaminase; CHB, chronic hepatitis $B ; C I$, confidence interval; ETV, entecavir; $\mathrm{HBeAg}$, hepatitis B envelope antigen; HBV, hepatitis B virus; HCC, hepatocellular carcinoma; IFN $\alpha$, interferon alpha; LAM, lamivudine; Ldt, telbivudine; TDF, tenofovir; WHO, World Health Organization.

Received: 15 June 2014; Revised: 26 July 2014; Accepted: 27 July 2014

DOI: $10.14218 / \mathrm{JCTH} .2014 .00022$.

*Correspondence to: Lun-Gen Lu, No 100, Haining Road, Department of Gastroenterology, Shanghai First People's Hospital, Shanghai Jiaotong University School of Medicine, Shanghai 200080, China. Tel: $+86-21-63240090$, Fax: $+86-21$ 63241357, Email: lungenlu1965@163.com
HBV-related cirrhosis, disease progression, and outcomes are closely associated with serum HBV DNA levels. Despite the availability since 1982 of a highly effective immunization program against HBV that decreased the incidence of $\mathrm{HBV}$, 5,6 the mortality from HBV-related cirrhosis and HCC has actually increased because of the high rate of HBV infection. ${ }^{7}$ Given the natural course of HBV infection and disease progression, timely management of $\mathrm{CHB}$ is of great importance for effective HBV therapy. The goal of antiviral treatment for HBV cirrhotic patients is to prevent disease progression to decompensated cirrhosis, end-stage liver disease, and HCC and to improve survival. ${ }^{8,9}$ Here, we review the significance of antiviral therapy for HBV-related cirrhosis and discuss concerns regarding the future management of HBV-related liver diseases.

\section{Progression of CHB from fibrosis to cirrhosis}

HBV primarily interferes with liver function by replicating in hepatocytes, and it is not directly cytopathic. However, infection with HBV does cause irritation and swelling (inflammation) of the liver. Acute hepatitis $B$ infection does not usually require treatment, and most adults clear the infection spontaneously..$^{10,11}$ If the virus remains in the blood for more than six months, this is chronic HBV infection. CHB is a dynamic state of interactions among HBV, hepatocytes, and the host immune system. CHB elicits varying degrees of predominantly lymphocytic infiltrates in the portal tracts associated with portal inflammation, interface hepatitis, and spotty lobular inflammation. ${ }^{12}$ Inflammation can lead to liver damage, including fibrosis (light to medium scarring of the liver), cirrhosis (extensive scarring of the liver), and liver cancer. Liver fibrosis refers to the hyperplasia of extracellular matrix, including collagen, in liver tissues. It is a scarring process that represents the liver's response to injury. Advanced liver fibrosis results in cirrhosis, liver failure, and HCC.

The replication of HBV in hepatocytes plays a key role in driving the progression of liver disease. Following development of fibrosis or compensated cirrhosis in patients with $\mathrm{CHB}$, liver disease may continue to progress and decompensation or HCC may occur, especially in those with active viral replication. If left untreated, approximately $20 \%$ will decompensate over five years and develop complications of end-stage liver disease. ${ }^{9}$ Once decompensation occurs, the cost for CHB therapy increases and the prognosis is poor. Therefore, the primary aim of therapy is to eliminate or permanently suppress HBV to reduce disease activity and thereby reduce the risk or slow the progression of liver disease. The ultimate long-term goal is to achieve a sustained 
Lu L.G.: Antiviral therapy liver cirrhosis hepatitis B virus infection

response to prevent or reduce the development of hepatic decompensation, cirrhosis, or HCC and to prolong survival. ${ }^{13}$

Although none of the available drugs can clear the infection, they can stop the virus from replicating, thus minimizing liver damage and decreasing the progression to cirrhosis, hepatic decompensation, and HCC. According to the guideline on prevention and treatment of chronic hepatitis $B$ in China (2010), ${ }^{14}$ the goal of antiviral therapy for CHB is to maximize the suppression or elimination of HBV, decrease liver inflammation and fibrosis, decrease the liver disease progression to cirrhosis, hepatic decompensation, HCC, and complication of end-stage liver disease, and prolong survival. The American Association for the Study of Liver Disease (AASLD) Practice Guidelines on Chronic Hepatitis B (2009) stated that to gain the goal of preventing cirrhosis, liver failure, and HCC, antiviral therapies are needed to restore liver function and improve survival in patients with $\mathrm{CHB} .{ }^{15} \mathrm{~A}$ recent meta-analysis by Mommeja-Marin et al. showed that antiviral therapy in hepatitis B envelope antigen ( $\mathrm{HBeAg}$ ) positive patients was associated with continuing improvement in liver histology. ${ }^{16}$ The 2012 update of the Asian-Pacific consensus statement on the management of $\mathrm{CHB}$ also stated that active HBV replication is the key driver of liver injury and disease progression, and thus, sustained viral suppression is of paramount importance. ${ }^{17}$ Oral antiviral therapy for $\mathrm{CHB}$ should be instituted regardless of HBV DNA level as early as possible to prevent the occurrence of hepatic decompensation and HCC. Therefore, the key to treating HBV-related cirrhosis is to decrease infectivity and pathogenicity of the virus by using antiviral agents.

\section{Serum HBV DNA level and risk of cirrhosis and HCC}

Cirrhosis develops during CHB disease progression as a result of hepatic inflammation and subsequent fibrosis. Risk factors associated with cirrhosis progression include viral replication, age, alcohol intake, co-infection with other viruses, and possibly HBV genotype. ${ }^{18}$ Several cohort studies have revealed the link between HBV replication and the development of cirrhosis and HCC. Multivariate analysis of a prospective study with $93 \mathrm{CHB}$ patients who developed cirrhosis during regular follow-up (mean 102 months) showed that persistent $\mathrm{HBeAg}$ seropositivity was significantly $(p=0.035)$ associated with the development of decompensation. The risk of hepatic decompensation was six-fold higher in persistently $\mathrm{HBeAg}$ positive patients than in patients who were seronegative for HBeAg at entry. ${ }^{19}$ Another populationbased prospective cohort study of 3,582 untreated hepatitis $B$-infected patients in Taiwan found that having a baseline HBV DNA level $>10^{4}$ copies $/ \mathrm{ml}$ was the strongest independent predictor of cirrhosis. ${ }^{13}$ During a mean follow-up time of 11 years, it was found that when the baseline HBV DNA level increased from $<300$ copies $/ \mathrm{ml}$ to $1 \times 10^{6}$ copies $/ \mathrm{ml}$, the cumulative incidence of cirrhosis significantly increased. For those with HBV DNA levels $<300$ copies $/ \mathrm{ml}$, $300-9.9 \times 10^{3}$ copies $/ \mathrm{ml}, 1 \times 10^{4}-9.9 \times 10^{4} \mathrm{copies} / \mathrm{ml}$, $1 \times 10^{5}-9.9 \times 10^{5}$ copies $/ \mathrm{ml}$, and $\geqslant 1 \times 10^{6}$ copies $/ \mathrm{ml}$, the incidence of cirrhosis was $4.5 \%, 5.9 \%, 9.8 \%, 23.5 \%$, and $36.2 \%$, respectively $(p<0.001)$, and the relative risk of cirrhosis was $1.0,1.4,2.5,5.9$, and 9.8 , respectively $(p<0.001)$. After adjusting for age, sex, smoking, alcohol, HBeAg status, and serum alanine transaminase (ALT) level, the multivariate-adjusted relative risk (95\% confidence interval, CI) of cirrhosis in all patients was 1.0, 1.4, 2.5,
5.6, and 6.5, respectively $(p<0.001)$. In the $2,923 \mathrm{HBeAg-}$ negative patients with a normal ALT level, the adjusted relative risk (95\% CI) of cirrhosis was $1.0,1.4,2.5,5.6$, and 6.6 , respectively $(p<0.001)$. These data suggested that active HBV replication following the onset of cirrhosis is an important prognostic factor for disease progression and that the progression to HBV-related cirrhosis is strongly correlated with the level of circulating virus. The risk for cirrhosis increases significantly with increasing HBV DNA levels and is independent of HBeAg status and serum ALT level.

\section{Intervention of HBV-related cirrhosis disease progression by antiviral therapy}

The immediate goal of antiviral therapy of $\mathrm{CHB}$ is to improve hepatic dysfunction and rescue patients from mortality. 9,14 Antiviral agents in use clinically are interferon alpha (IFN $\alpha$ ) and nucleos(t)ide analogues, such as lamivudine (LAM), adefovir dipivoxil (ADV), telbivudine (LdT), entecavir (ETV) and tenofovir (TDF). Both IFN $\alpha$ and nucleos(t)ide analogues can be effective, but the duration of treatment, side effects, treatment costs, and drug resistance must be taken into consideration when determining an optimal choice based on individual patient characteristics. ${ }^{20}$

An effective antiviral agent should be able to achieve potent and durable viral suppression to low or undetectable levels and possess a high genetic barrier to prevent the occurrence of resistance. ${ }^{21}$

\section{IFN}

Long-term follow-up studies of IFN therapy show inconsistent results. ${ }^{22-29}$ An early pilot study by Ikeda et al. demonstrated that IFN $\alpha$ decreased hepatocellular carcinogenesis in patients with cirrhosis caused by HBV infection. ${ }^{23}$ Of the 313 patients evaluated, the cumulative occurrence of HCC was significantly lowered by the intermittent administration of IFN $\alpha$ $(n=94)$ compared with those receiving no therapy $(n=219)$ at three $(4.5 \%$ vs. $13.3 \%)$, five $(7.0 \%$ vs. $19.6 \%)$, and 10 years $(17.0 \%$ vs. $30.8 \%)$, respectively. The rate of HCC development in the treated group was significantly lower than that of the untreated group $(P=0.0124)$. In another study of 233 HBeAg-positive IFN-treated patients ( $8.1 \%$ with cirrhosis) and 233 matched controls ( $10.7 \%$ with cirrhosis), ${ }^{24}$ the incidence of HCC appeared to be reduced by therapy $(2.7 \%$ vs. $12 \%$ in controls, $p<0.01$ ) but was limited to patients with pre-existing cirrhosis. However, other studies have shown no benefit of IFN $\alpha$ in the prevention of HCC in HBV infected patients because $\mathrm{HBeAg}$ seroconversion was used as the endpoint of treatment and detectable serum HBV DNA, a relevant risk factor for $\mathrm{HCC}$, remained in most of the patients. ${ }^{13}$ It was also reported that pegylated (PEG)-IFN $\alpha$ did not influence the development of HCC in patients with mild or moderate fibrosis. ${ }^{25-27,30}$ Thus, the efficacy of IFN $\alpha$ in preventing HBV-related HCC is controversial, and there are several limitations to most studies with positive results. A recent meta-analysis ${ }^{13}$ evaluated the efficacy and safety of adjuvant IFN therapy in patients with HCC who have undergone hepatic resection, transplantation, or locoregional ablation therapy. It showed that adjuvant IFN therapy can improve both recurrence-free survival and overall survival. However, the benefits of using this agent should be weighed against its side effects. 
IFN $\alpha$ is not recommended for patients with decompensated cirrhosis. No significant benefit was found in two studies evaluating the use of IFN treatment in HBV patients with Child-Pugh B or C cirrhosis. ${ }^{31,32}$ Virologic and biochemical responses were observed in only $33 \%$ and $0 \%$ of ChildPugh $B$ and $C$ patients, respectively. ${ }^{32}$ In addition, even at low doses of IFN $\alpha$, severe side effects due to bacterial infections and worsening liver failure occurred. ${ }^{32}$ At present, IFN therapy is now contraindicated for the treatment of decompensated cirrhotic patients, even with the availability of safer alternative agents and modalities.

\section{Nucleos(t)ide analogues}

Currently, the use of nucleos(t)ide analogues has been widely reported for antiviral therapy in active and decompensated HBV-related cirrhosis. Relative to placebo therapy, treatment with nucleos(t)ide analogues offered improved liver histology and survival benefits.

A recent study investigated long-term outcomes and prognostic factors in patients with HBV-related cirrhosis in the era of oral nucleos(t)ide analog antiviral agents. ${ }^{33}$ It was found that in $78 \%$ of patients who received antiviral treatment, sustained viral suppression (serum HBV DNA < $10^{5}$ copies $/ \mathrm{mL}$ ) was achieved during a mean follow-up period of 46 months. The five year cumulative incidences of death, hepatic decompensation, and HCC were $19.4 \%$ vs $43.9 \%$ (log-rank $P<0.001), 15.4 \%$ vs $45.4 \%(p=0.001)$, and $13.8 \%$ vs $23.4 \%(p=0.074)$, respectively. Therefore, oral antiviral agents have improved the prognosis of patients with HBV-related cirrhosis.

In a study with $651 \mathrm{CHB}$ patients who had confirmed cirrhosis or advanced fibrosis, LAM therapy was shown to delay clinical progression by significantly reducing the incidence of hepatic decompensation and the risk of HCC. ${ }^{34}$ The patients were randomly assigned in a $2: 1$ ratio to receive LAM (100 mg per day, $n=436$ ) or placebo $(n=215)$ for a maximum of five years. An increase of two points or more in the Child-Pugh score was pre-set as the primary endpoint for disease progression. Due to a significant difference between treatment groups in the number of end points reached, the study was terminated after a median treatment duration of 32.4 months (range, 0 to 42 ). At the time of data analysis, the Child-Pugh score increased in $3.4 \%$ of patients receiving LAM and $8.8 \%$ of those receiving placebo (hazard ratio, 0.45 ; $P=0.02)$. LAM treatment significantly reduced the rate of disease progression relative to placebo controls $(7.4 \%$ vs. $18.0 \%, p=0.001$ ) and HCC development (3.9\% vs. $7.4 \%$ placebo controls, hazard ratio, $0.49 ; p=0.047)$. Overall, the magnitude of protection conferred by LAM is substantial, with an approximately $50 \%$ reduction in disease progression. This study suggested that long-term LAM treatment can prevent complications of $\mathrm{CHB}$ and reduce the incidence of hepatic decompensation and HCC.

However, LAM-resistant HBV mutations with amino acid substitutions in the tyrosine-methionine-aspartate-aspartate (YMDD) motif of the RNA-dependent DNA polymerase (rtM204 I/V) developed in 49\% of the patients treated with LAM, and the Child-Pugh score was more likely to increase in patients with these mutations than in patients without the mutations $(7 \%$ vs. $<1 \%)$. The emergence of rtM204 I/V is followed by viral breakthrough and ALT elevation ( $>5$ times the upper limit of normal) in over $90 \%$ of the patients. ${ }^{35} \mathrm{~A}$ study by Liaw et al. ${ }^{36}$ compared the efficacy and safety profile of ADV monotherapy in 18 cirrhotic patients and ADV add-on LAM therapy in 10 comparable cirrhotic patients with LAMresistant rtM204 I/V. After switching to ADV monotherapy or ADV add-on, Child-Pugh's score, serum ALT, bilirubin, albumin, and HBV DNA response (defined as HBV DNA decreased to below $10^{5}$ copies $/ \mathrm{mL}$ or $\geqslant 2 \log _{10}$ reduction form baseline) improved significantly $(p<0.01)$. A transient ALT flare without concurrent changes in serum bilirubin or prothrombin time was observed in only two patients $(11 \%)$.

Another three large, randomized, multicenter, phase III studies $^{37}$ evaluated the efficacy and safety of entecavir in CHB patients and advanced liver fibrosis/cirrhosis. Histologic improvement was observed in $57 \%, 59 \%$, and $43 \%$ of nucleos(t)ide-naïve $\mathrm{HBeAg}(+)$ patients, nucleos(t)ide-naive $\mathrm{HBeAg}(-)$ patients, and LAM-refractory $\mathrm{HBeAg}(+)$ patients with ETV treatment. The overall performance in histologic, virologic, biochemical, and serologic outcomes in ETVtreated groups were better than those observed in LAMtreated patients with advanced liver fibrosis/cirrhosis, which were comparable with the overall study populations in each trial.

A recent randomized, open-label comparative study ${ }^{38}$ with a mean duration of 280 weeks comparing ETV and ADV therapy was performed in CHB subjects with hepatic decompensation (Child-Pugh score $\geqslant 7$ ). It was found that $96 \%$ of patients achieved liver histological improvement by reducing necroinflammation (a decrease of Ishak score $\geqslant 1$ ). The ETV group exhibited a greater change from baseline in HBV DNA levels for the primary and key secondary virologic endpoints and had a higher proportion of subjects achieve HBV DNA < 300 copies/mL at weeks 24 (ETV 49\%; ADV 16\%; $P<0.0001$ ) and 48 (ETV 57\%; ADV 20\%; $P<0.0001$ ). Eight-six percent of patients achieved ALT $<1$-fold of the upper limit of normal. Approximately two-thirds of subjects in both groups showed improvement/stabilization in Child-Pugh status. Therefore, both ETV and ADV treatments provided clinical improvements with suppression of serum HBV DNA level. Given the favorable safety profile, potency, and high barrier to resistance, ETV appears to be a favorable choice for naïve patients who have decompensated liver disease.

Marcellin et al. ${ }^{39}$ recently reported the results of a five year open-label follow-up study of a double-blind phase III trial of the nucleotide analogues tenofovir disoproxil fumarate and adefovir dipivoxil for chronic hepatitis B. Of the 348 patients who had paired biopsies both at baseline and at year five, 304 $(87 \%)$ had histological improvement, defined as a $\geqslant 2$-point decrease in Knodell necroinflammatory score (0-18) and no worsening in Knodell fibrosis score (0-4). Moreover, 176 $(51 \%)$ had regression of fibrosis, defined as $a \geqslant 1$-point decrease in Ishak fibrosis score (0-6) at year five. Of note, 71 of $96(74 \%)$ patients who had cirrhosis at baseline no longer had cirrhosis at year five. In the on-treatment analyses, $98 \%$ of the patients had HBV DNA <169 copies/ml ( $35 \mathrm{IU} / \mathrm{ml})$. These results are remarkable and demonstrate that longterm therapy with a potent antiviral agent that has a high genetic barrier to resistance can maintain viral suppression in nearly $100 \%$ of patients.

\section{Treatment selection for HBV-related cirrhosis}

In the management of HBV related cirrhosis, viral suppression with safe and effective antiviral agents is essential as patients with HBV-related cirrhosis have compromised liver function and may manifest with endocrine dyscrasia, 
jaundice, portal hypertension, bleeding from varices, hepatic encephalopathy, and bacterial peritonitis. In addition, side effects from antiviral treatments should also be weighed. Once drug-resistance occurs, the treatment regimen should be adjusted or a second agent should be added as an alternative. Recent studies showed that the one to five year occurrences of drug resistance were $23 \%, 46 \%, 55 \%, 71 \%$, and $65 \%$ in LAM-naïve HBeAg-positive patients, ${ }^{40} 0 \%, 3 \%$, $11 \%, 18 \%$, and $29 \%$ in ADV-naïve HBeAg-negative patients, ${ }^{41}$ and $0.2 \%, 0.5 \%, 1.2 \%, 1.2 \%, 1.2 \%$ in ETVnaïve $\mathrm{HBeAg}$-positive and ETV- naïve $\mathrm{HBeAg}$-negative patients. ${ }^{42}$ The one to two year occurrences of drug resistance were $5 \%$ and $22 \%$ in LdT-naïve HBeAg-positive patients, whereas they were $2 \%$ and $9 \%$, respectively, in LdTnaïve $\mathrm{HBeAg}$-negative patients. ${ }^{43}$

\section{Conclusions}

Taking both efficacy and drug resistance profiles into account, an ideal antiviral treatment for HBV-related cirrhosis should be safe and affordable in order for long-term use to achieve a high rate of sustained HBV suppression with a low risk of drug resistance. With the ultimate goal to confer beneficial effects on liver functions and survival, the optimal choice for HBVrelated cirrhosis in each case depends on specific patient characteristics.

\section{Acknowledgement}

This work was supported by the National Key Technologies Research and Development Program of China during the 11th/ 12th Five-year Plan Period (no. 2008ZX1002-006, 2012ZX10002007-001-040 and 2013ZX10002004-002-003).

\section{Conflict of interest}

None

\section{Author contributions}

Writing the paper (LGL).

\section{References}

[1] Lavanchy D. Hepatitis B virus epidemiology, disease burden, treatment, and current and emerging prevention and control measures. J Viral Hepat 2004; 11:97-107. doi: 10.1046/j.1365-2893.2003.00487.x.

[2] Mohamed R, Desmond P, Suh DJ, Amarapurkar D, Gane E, Guangbi Y, Hou JL, et al. Practical difficulties in the management of hepatitis $B$ in the Asia-Pacific region. J Gastroenterol Hepatol 2004;19:958-969. doi: 10.1111/j.14401746.2004.03420.x.

[3] Schilsky ML. Hepatitis B "360". Transplant Proc 2013;45:982-985. doi: 10.1016/j.transproceed.2013.02.099.

[4] Lok AS. The maze of treatments for hepatitis B. N Engl J Med 2005;352: 2743-2746. doi: 10.1056/NEJMe058119.

[5] Ni YH, Chang MH, Wu JF, Hsu HY, Chen HL, Chen DS. Minimization of hepatitis $B$ infection by a 25-year universal vaccination program. J Hepatol 2012;57: 730-735. doi: 10.1016/j.jhep.2012.05.021.

[6] Ott J], Stevens GA, Groeger J, Wiersma ST. Global epidemiology of hepatitis B virus infection: new estimates of age-specific HBsAg seroprevalence and endemicity. Vaccine 2012;30:2212-2219. doi: 10.1016/j.vaccine.2011.12.116.

[7] Ly KN, Xing J, Klevens RM, Jiles RB, Ward JW, Holmberg SD. The increasing burden of mortality from viral hepatitis in the United States between 1999 and 2007. Ann Intern Med 2012;156:271-278. doi: 10.7326/0003-4819156-4-201202210-00004.
[8] Lok ASF. Hepatitis: Long-term therapy of chronic hepatitis B reverses cirrhosis. Nat Rev Gastroenterol Hepatol;2013;10:199-200. doi: 10.1038/ nrgastro.2013.13.

[9] European Association for the Study of The Liver EASL clinical practice guidelines: Management of chronic hepatitis B virus infection. J Hepato 2012;57:167-185.

[10] LeFevre ML, U.S. Preventive Services Task Force. Screening for Hepatitis B Virus Infection in Nonpregnant Adolescents and Adults: U.S. Preventive Services Task Force Recommendation Statement. Ann Intern Med 2014;161: 58-66. doi: 10.7326/M14-1018.

[11] Hollinger FB, Lau DT. Hepatitis B: the pathway to recovery through treatment. Gastroenterol Clin North Am 2006;35:895-931. doi: 10.1016/ j.gtc. 2006.10.002.

[12] Te HS. Diagnostic Approach to Hepatitis B Virus (HBV) Infection. North American Journal of Medicine and Sci 2011;4:27-34. doi: 10.7156/v4i1p027.

[13] Liaw YF. Impact of therapy on the long-term outcome of chronic hepatitis B. Clin Liver Dis 2013;17:413-423. doi: 10.1016/j.cld.2013.05.005.

[14] Chinese Society of Hepatology CMA, Chinese Society of Infectious Diseases CMA. The guideline of prevention and treatment for chronic hepatitis B (2010 version). Zhonghua Gan Zang Bing Za Zhi. 2011;19(1):13-24

[15] Lok AS, McMahon B]. Chronic hepatitis B:update 2009. Hepatology 2009;50: 661-662. doi: 10.1002/hep.23190.

[16] Mommeja-Marin H, Mondou E, Blum MR, Rousseau F. Serum HBV DNA as a marker of efficacy during therapy for chronic HBV infection: analysis and review of the literature. Hepatology 2003;37:1309-1319. doi: 10.1053/ jhep.2003.50208.

[17] Liaw YF, Kao JH, Piratvisuth T, Chan HLY, Rong-Nan Chien RN, Liu CJ, etal. AsianPacific consensus statement on the management of chronic hepatitis B: a 2012 update. Hepatol Int 2012;6:531-561. doi: 10.1007/s12072-012-9365-4.

[18] Fung SK, Lok AS. Management of patients with hepatitis B virus-induced cirrhosis. J Hepatol 2005;42 (Suppl 1):S54-64. doi: 10.1016/ j.jhep.2004.11.014.

[19] Chen YC, Chu CM, Yeh CT, Liaw YF. Natural course following the onset of cirrhosis in patients with chronic hepatitis B: a long-term follow-up study. Hepatol Int 2007;1:267-273. doi: 10.1007/s12072-007-5001-0.

[20] Lin CL, Kao JH. Recent advances in the treatment of chronic hepatitis B. Expert Opin Pharmacother 2011;12:2025-2040. doi: 10.1517/ 14656566.2011.590474.

[21] Zoulim F, Locarnini S. Management of treatment failure in chronic hepatitis B. J Hepatol 2012;56 (Suppl 1):S112-122. doi: 10.1016/S0168-8278(12)60012-9.

[22] Tangkijvanich $P$, Thong-ngam D, Mahachai V, Kladchareon N, Suwangool $P_{,}$ Kullavanijaya P. Long-term effect of interferon therapy on incidence of cirrhosis and hepatocellular carcinoma in Thai patients with chronic hepatitis B. Southeast Asian J Trop Med Public Health 2001;32:452-458.

[23] Ikeda K, Saitoh S, Suzuki Y, Kobayashi M, Tsubota A, Fukuda M, Koida I, et al. Interferon decreases hepatocellular carcinogenesis in patients with cirrhosis caused by the hepatitis B virus: a pilot study. Cancer 1998;82:827-835. doi: 10.1002/(SICI)1097-0142(19980301)82:5<827: :AID-CNCR5>3.0.CO;2-G.

[24] Lin SM, Yu ML, Lee CM, Chien RN, Sheen IS, Chu CM, et al. Interferon therapy in $\mathrm{HBeAg}$ positive chronic hepatitis reduces progression to cirrhosis and hepatocellular carcinoma. J Hepatol 2007;46:45-52. doi: 10.1016/ j.jhep.2006.08.021.

[25] Yuen MF, Hui CK, Cheng CC, Wu CH, Lai YP, Lai CL. Long-term follow-up of interferon alfa treatment in Chinese patients with chronic hepatitis $B$ infection: The effect on hepatitis $B$ e antigen seroconversion and the development of cirrhosis-related complications. Hepatology 2001;34:139145. doi: 10.1053/jhep.2001.25273.

[26] Truong BX, Seo Y, Kato M, Hamano K, Ninomiya T, Katayama M, et al. Longterm follow-up of Japanese patients with chronic hepatitis $B$ treated with interferon-alpha. Int J Mol Med 2005; 16:279-284.

[27] Lin SM, Sheen IS, Chien RN, Chu CM, Liaw YF. Long-term beneficial effect of interferon therapy in patients with chronic hepatitis B virus infection. Hepatology 1999;29:971-975. doi: 10.1002/hep.510290312.

[28] Camma C, Giunta M, Andreone P, Craxi A. Interferon and prevention of hepatocellular carcinoma in viral cirrhosis: an evidence-based approach. J Hepatol 2001;34:593-602. doi: 10.1016/S0168-8278(01)00005-8.

[29] Yang YF, Zhao W, Zhong YD, Xia HM, Shen L, Zhang N. Interferon therapy in chronic hepatitis $\mathrm{B}$ reduces progression to cirrhosis and hepatocellular carcinoma: a meta-analysis. J Viral Hepat 2009;16:265-271. doi: 10.1111/j.1365-2893.2009.01070.x.

[30] Krogsgaard K. The long-term effect of treatment with interferon-alpha $2 a$ in chronic hepatitis B. The Long-Term Follow-up Investigator Group. The European Study Group on Viral Hepatitis (EUROHEP). Executive Team on Anti-Viral Treatment. J Viral Hepat 1998;5:389-397. doi: 10.1046/j.13652893.1998.00118.x.

[31] Hoofnagle JH, Di Bisceglie AM, Waggoner JG, Park Y. Interferon alfa for patients with clinically apparent cirrhosis due to chronic hepatitis B. Gastroenterology 1993;104:1116-1121.

[32] Perrillo R, Tamburro C, Regenstein F, Balart L, Bodenheimer H, Silva M, et al. Low-dose, titratable interferon alfa in decompensated liver disease caused 
by chronic infection with hepatitis B virus. Gastroenterology 1995;109:908916. doi: 10.1016/0016-5085(95)90401-8.

[33] Kim CH, Um SH, Seo YS, Jung JY, Kim JD, Yim HJ, Keum B, et al. Prognosis of hepatitis B-related liver cirrhosis in the era of oral nucleos(t)ide analog antiviral agents. J Gastroenterol Hepatol 2012;27:1589-1595. doi: 10.1111/j.1440-1746.2012.07167.x.

[34] Liaw YF, Sung J], Chow WC, Farrell G, Lee CZ, Yuen H, Tanwandee T, et al. Lamivudine for patients with chronic hepatitis $\mathrm{B}$ and advanced liver disease. N Engl J Med 2004;351:1521-1531. doi: 10.1056/NEJMoa033364.

[35] Liaw YF. The current management of HBV drug resistance. J Clin Virol 2005; 34 (Suppl 1):S143-146. doi: 10.1016/S1386-6532(05)80025-3.

[36] Liaw YF, Lee CM, Chien RN, Yeh CT. Switching to adefovir monotherapy after emergence of lamivudine-resistant mutations in patients with liver cirrhosis. J Viral Hepat 2006;13:250-255. doi: 10.1111/j.1365-2893.2005.00687.x.

[37] Schiff E, Simsek $H$, Lee WM, Chao YC, Sette H, Jr., Janssen HL, et al. Efficacy and safety of entecavir in patients with chronic hepatitis B and advanced hepatic fibrosis or cirrhosis. Am J Gastroenterol 2008;103: 2776-2783. doi: 10.1111/j.1572-0241.2008.02086.x.

[38] Liaw YF, Raptopoulou-Gigi M, Cheinquer H, Sarin SK, Tanwandee T, Leung N, et al. Efficacy and safety of entecavir versus adefovir in chronic hepatitis $\mathrm{B}$ patients with hepatic decompensation: a randomized, open-label study. Hepatology 2011;54:91-100. doi: 10.1002/hep.24361.

[39] Marcellin P, Gane E, Buti M, Afdhal N, Sievert W, Jacobson IM, et al. Regression of cirrhosis during treatment with tenofovir disoproxil fumarate for chronic hepatitis B: a 5-year open-label follow-up study. Lancet 2013; 381:468-475. doi: 10.1016/S0140-6736(12)61425-1.

[40] Lok AS, Lai CL, Leung N, Yao GB, Cui ZY, Schiff ER, et al. Long-term safety of lamivudine treatment in patients with chronic hepatitis B. Gastroenterology 2003;125:1714-1722. doi: 10.1053/j.gastro.2003.09.033.

[41] Hadziyannis SJ, Tassopoulos NC, Heathcote EJ, Chang TT, Kitis G, Rizzetto M, et al. Long-term therapy with adefovir dipivoxil for HBeAg-negative chronic hepatitis B for up to 5 years. Gastroenterology 2006;131:1743-1751. doi: 10.1053/j.gastro.2006.09.020.

[42] Tenney DJ, Rose RE, Baldick CJ, Pokornowski KA, Eggers BJ, Fang J, et al. Long-term monitoring shows hepatitis $B$ virus resistance to entecavir in nucleoside-naive patients is rare through 5 years of therapy. Hepatology 2009;49:1503-1514. doi: 10.1002/hep.22841.

[43] Lai CL, Gane E, Liaw YF, Hsu CW, Thongsawat S, Wang Y, et al. Telbivudine versus lamivudine in patients with chronic hepatitis B. N Engl J Med 2007; 357:2576-2588. doi: 10.1056/NEJMoa066422. 